\title{
Optimizing Project Delivery through Augmented Reality and Agile Methodologies
}

\author{
Aseel Hussien ${ }^{1}$, Matthew Tucker ${ }^{2}$, Alison Cotgrave ${ }^{1}$, Mohammed Al-Khafajiy $^{3}$, Thar Baker Shamsa ${ }^{3}$ \\ ${ }^{1}$ Department of Built Environment, Liverpool John Moores University, Liverpool, UK \\ Email:A.Hussien@ljmu.ac.uk, A.J.Cotgrave@ljmu.ac.uk \\ ${ }^{2}$ Business School, Liverpool John Moores University, Liverpool, UK; Email:M.P.Tucker@ljmu.ac.uk \\ ${ }^{3}$ Department of Computer Science, Liverpool John Moores University, Liverpool, UK \\ Email:M.D.Alkhafajiy@2016.ljmu.ac.uk, T.Baker@1jmu.ac.uk
}

\begin{abstract}
The construction sector, which has a long history to use visualisation to envisage proposed designs and project delivery, is beginning to see the benefits of augmented reality and agile project management methodologies. This study investigated the benefits of augmented reality and agile project management methodologies. Convergent design method was considered valuable and the most straightforward for this study, as different types of quantitative and qualitative data were required to be collected and analysed. The participants drawn from the construction sector revealed a number of augmented and agile determinants that facilitated the delivery of construction and integration of project teams. The participants suggested that the proposed ARGILE framework increases client understanding of the tasks output, increases client involvement and collaboration with the project team. It was further established that the proposed ARGILE framework enhances project time management, embeds the client and empowers multidisciplinary team, increases collaboration and communication.
\end{abstract}

\section{INTRODUCTION}

Overrun project time and budget, and the poor performance are a common problem in construction industry. As such, these problems have attracted the interest of several researchers in order to find the reasons behind it [1]. Some results showed that stakeholders might be the causes of the poor performance. While others have shed the light on the way projects are managed through [2], [3], and noted that there are still several management approaches used today in the construction industry including waterfall, lean construction and BIM. Other researchers clearly indicated in their recent studies that; the current management approaches are still underestimate the impact of the dynamic construction environments [2], [1].

In support of this notion, Shah et al. [4], discovered that 29\% of projects were delayed in the delivery due to poor construction planning, scheduling and lack of visual planning system. Ross, et al. [3] stated that construction-planning problems also increased as the projects are still managed with antiquated management. Several scholars [5], [6] have shown that the industry is suffering the lack of collaboration, even with the implementation of the building information modelling (BIM) and other digital representations of physical and functional characteristics in the construction context.

978-1-5386-6712-5/18/\$31.00 (C)2018 IEEE
In addition, researchers found that several countries, including UK, Netherlands, USA, Finland, and Australia, there are still uncertainties about the BIM execution approaches, strategy, performance, identifying and prioritizing their respective requirements [7]. Besides, BIM strategic plan required two elements; an inclusive set of decision-making principles, and

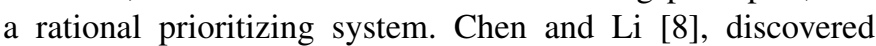
that current BIM assessments have limitations relating to the decision-making and prioritizing system. Other literatures posit that construction contractors are using new technologies mainly to automate old design processes rather than change the way in which they communicate their designs. However, Sun et al. [9] argued that there are still several limitations in the factors of the BIM process in the construction industry including technology, cost, management, human resource, and legislation.

From the discussions above, it is clear that there are still limitations in the collaboration and communication within the design and construction process leading to weakness in the decision-making, which affects the project outcome. In addition, visual understanding within the design process helps in capturing, representing, and sharing the design information, and further assists in tracking the changes in the design and effects the design decision-making [10]. The lack in visual understanding has taken a negative impact on the project development, collaboration and design decision-making, especially when it is linked to unprofessional clients or those unable to fully understand the design presentation methods used by the professional project team.

There is a vital need to have better controls on the collaboration, communication, information sharing, decision-making process, and the visual understanding. It is essential to develop a flexible and adaptive management method that will enhance collaboration, communication, information sharing, and empower visual understanding among construction practitioners. Therefore, a research question was raised: How can augmented reality [11] and agile project management [12] assist clients, design and construction teams in collaboration, visual understanding, data sharing, communication and decision-making process? Two research aims would be thus achieved based on the question as:

- To determine the benefits of augmented reality [11] and 
agile project management methodologies [12].

- To make empirical contributions to the development and advancement of data sharing, visual understanding and decision-making process, by proposing an ARGILE framework.

This article presents the development of one ARGILE conceptual framework that can combine augmented reality technology and agile project management philosophy to overcome the above-mentioned limitation.

\section{LiterATURE REVIEW}

\section{Agile management approach}

Agile is a practice-based methodology for effective modeling and documentation. Its is a collection of practices, guided by principles and values, which meant to be applied by professionals on a day-to-day basis [12]. It is a rapid and adaptive response to change effective communication among all clients and project teams, drawing the client into the team. In addition, it can help form a team, which is in control of the work achieved [13]. Agile works by breaking projects down into tasks of user functionality to help in developing the project tasks gradually from the start of the project, ordering the tasks and prioritizing them and then continuously testing and delivering them in short time cycles [14], [15].

\section{Agile principles}

The main agile principles [14] are: • Time-boxed, • Iterative approach, • Incremental delivery • Prioritize little tasks. - Focus of testing.

Users of agile methodology, never stop analysis, designing, and testing of the project tasks [12]. So, as long as there are tasks to build, and the requirements to deliver, these activities continue for the duration of the project. In other words, it means starting with simple tasks and accumulating them incrementally over time. Helping to develop any project and accept changes at any stage [16].

Practitioners using the agile methodology have to balance conflicting demands; while the four most common demands are; time, cost, scope, and quality [17]. Trying to fix all four demands at the outset of a project is unrealistic, as fixing everything is the reason for many project failures: as such in agile methodology, it is important at the start of the project to fix the time, cost, and the quality [18]. In the traditional method (e.g. waterfall), the feature is fixed while the time and cost are subject to variation. Furthermore, the quality also tends to become an unplanned variable mainly because testing is typically left to the end of the project. Figure 1 shows the differences between the traditional approach and the agile approach. The agile approach will always deliver a viable solution on time, cost (on budget) as long as the practices of MoSCow and Timed boxing are followed [19]. MoSCoW is a prioritization technique that facilitates the attainment of common understanding among stakeholders on the importance they place on the delivery of each project requirement [19].

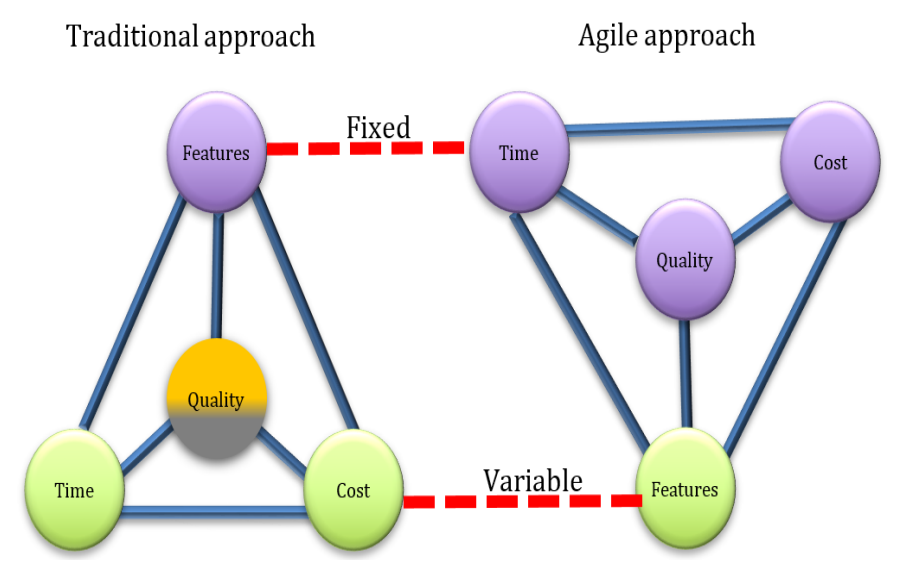

Fig. 1. Difference between traditional approach and agile approach

\section{Agile in the construction industry}

The above-mentioned agile principles are important in attaining the aim of an actual cost reduction in the design and construction processes [20]. However, there are very limited studies available of agile within construction projects, most of which were focused on its principles [1]. Furthermore, the principles of agile could achieve significant effect if they have been implemented through the pre-design, the design, and the construction phases [21]. Agility can stress different values to lean, typically learning, rapid configuration and change.

During the early stages of construction project, a number of major concerns need to be addressed. These include the concept development, procurement strategy, time and cost, and the preparation of a brief [22]. Implementing the agile approach from early pre-design phase of projects would enhance the client's involvement and interaction, which would consequently improve the project outcomes and the increase of overall client's satisfaction [23], [24], [25]. The time-boxed principle would offer the construction industry an approach in keeping track of the project's development. This principle will also inspire individuals since they are given more duties, and more importantly a suitable level of authority. In the end, this could lead to better-developed design and projects since the project team feels more inspired to achieve the client requirements, and detect errors by visually testing the tasks before starting the work on site [26]. The agile method may be easier to use than the traditional method since the project can start small and then continuously add to the amount or improve the current requirements, design and materials used. In addition, it can also focus on the earliest stages of a project where project team really needs to find the underlying cause of what the client is looking for. This approach emphasizes developing a solid vision for the project and establishing a thorough communication plan [27].

Several studies have justified the importance of the implementation of agile in the construction industry [25], in that the agile process improves on-time delivery and the client satisfaction by $23 \%$, increases the construction predictability by $40 \%$, and most importantly increases organizational skills 
of both management and development personnel by $97 \%$. As mentioned by Owen et al. [25], the construction industry would benefit from the adoption of agile approach. Sohi et al. [20] showed that when applying the agile approach to construction projects, the project benefits from the ability to react to changes in a systematic and structured way, and in the meantime creates more efficiency in project management as unnecessary tasks and activities will be rejected. Loforte and Tim [21] indicated that agile methods have been proven successful in increasing client and customer satisfaction. Similarly, Sohi et al. [20] explored the implicit usage of lean and agile in coping with complexity. Part of this study disclosed that increasing the project complexity needs a tailored project management methodology, and therefore implementing the agile method is assumed to be the solution. From the discussions above, it is clear that the use of the agile approach in the delivery of construction projects has a positive impact on the on-time delivery, and improves client satisfaction, collaboration and enhances project development.

\section{Augmented reality}

Augmented reality is a novel system that produces and generates a merged view for the user; whilst it is the mixture of the real scene viewed by the user and a virtual scene generated by the computer that enhances the scene with additional information [39]. Within the context of this study, augmented reality has been considered as an enhanced version of reality created by the use of technology to overlay digital project data on an image. According to Hussein et al. [29], augmented reality is a novel approach to the integration and simulation processes of monitoring and viewing the real world and the virtual object (i.e. project).

Research has identified different benefits and abilities for augmented reality in the areas of Architecture, Engineering Construction (AEC) industry, such as virtual site visit, better visual understanding, satisfying clients and increasing their expectations [30], [31], [32]. Using smart devices can help the user to move freely while working on site. The use of GPS and orientation tracker technology synchronized with the smart devices would give extra and significant data input of the user's location and surroundings. The benefit of augmented reality systems lies in their ability to help view the features from different points so that they are more suitable to the job than a map or drawing; whilst it is an efficient tool to coordinate and share information [28]. In recent years, there have been many efforts to improve the efficiency of numerous field tasks, through the improvement of the construction process [33].

\section{Research Methods Implemented}

To achieve the aims of this study, mixed research methods have been used. The research started with parallel quantitative and qualitative methods, this approach guided the research work into a better and larger understanding of the problem. Convergent design was considered valuable and the most straightforward of the mixed methods design as different types of data are collected, analysed separately and independently during one stage [34]. Although the convergent design is a straightforward research approach, and it is a direct method to define, implement and report [35]. The convergent parallel approach was conceptualized as a triangulation design where two different research methods (qualitative and quantitative) that could be used to obtain a triangulated validation of the conceptual framework implemented in the research.

The rationale for adopting such an approach is first, it allows the triangulation of data and assures its validity. Second, the various methods used are complimentary; one method strengthening the other. Thirdly, mixed research methods make it possible to elicit supplemental data that strengthen research effectiveness [34].

\section{Phase 1-quantitative questions}

A survey questionnaire was developed to examine the implementation of AR technology as a visual-testing tool through different phases of the design- construction processes. The questionnaire consisted of 28 closed questions, designed in a simple language format, and employed the use of the Likert unidimensional scale and participants were asked to indicate the level of agreement on each factor using a scale from 1-3: Disagree 1; Neutral 2; Agree 3.

The questionnaire data were collected electronically for nine months via the use of Bristol Online Survey (BOS). The total sample size count was 350 individuals from the construction sectors, with 163 valid responses collected. However, the response rate is calculated based on the sampling size required (response received/sampling size) 46.5\%. The obtained data were analyzed with the IBM/SPSS package using several descriptive statistics in order to show the frequencies, mean and percentages.

\section{Phase 2-qualitative feedback}

A semi-structure interview were developed, the interviews were discussion orientated to evaluate the current project management strategies implemented wwithin the designconstruction stages. The questions focused on the barriers affecting good collaboration and communication, the software used and the RIBA stages implemented. Eighteen professionals took part in the research, each interview lasted for 30-40 minutes and was conducted based on the previously identified questions.

Majority of the participants interviewed were from architecture firms with different sizes, which are based in the UK. The participants first identified their role, and the challenges issues facing their role. Second the participants presented their opinions of the current tools and software they are using and which stage of the RIBA working plan it has been used for. The interviews were semi-structured in order to address a specific topic, but at the same time it allowed any emergent themes to develop [34]. In order to increase the quality of chosen participant, the researchers opted to use probabilitysampling strategy. Probability sampling method is any method of sampling that utilizes some form of random sampling selection [34]. In order to have a random selection method, 
the researchers set up some procedure assuring that different units in study population have equal probabilities of being chosen [34] .

\section{RESULTS}

\section{A. Statistical analysis of quantitative questions}

This section provides a detailed description and analysis of each part of the questionnaire.

As can be seen in Table I, the gender of the 163 participants was male $(41.1 \%)$, and female $(58.9 \%)$. The table shows that the age distributions of the 163 participants were $<50(12.9 \%)$, 41-50 (21.5\%), 31-40 (23.9\%), 21-30 (27.6\%), >20 (14.1\%). The job category was divided into three sub-categories: design team $(65.1 \%)$, site team $(20.9 \%)$ and client $(8.6 \%)$. The sub category of the job role was as follows: architects $(35.6 \%)$, service engineer $(17.8 \%)$, structure engineer $(11.7 \%)$, contractors $(12.3 \%)$, sub-contractors $(8.6 \%)$ and client $(9.8 \%)$.

As can be observed in Table I, there was a diverse pool of participants. Participants working experience ranged from a minimum of less than one year to a maximum of 50 years. The main advantage of these samples was that each participant has work experiences in the construction sector. All participants were considered to have practical experience and understanding of augmented reality as a visualization tool. Table I presents statistical summary of augmented reality users. As shown in Table I, a large amount of augmented reality users (68) were within the $>20-30$ age bracket, whilst Table II indicates that a larger number of architects were using augmented reality compared to other practitioners.

Pearson Correlation test was used to determine the relationship of the variables with the implementation of augmented reality, also the direction of the relationship correlation. The descriptive statistical analysis includes, means, standards deviation, $\mathrm{r}$ value, and $p$ value (significance), were used to test the relation between variables from the factors (independent variables) and the extent to which the factors are present (dependent variables). Pearson correlation coefficients (r) value range between $(-1$ to +1$)$ the sign in front of the number indicates to a positive or negative correlation, and the value indicates the strength of the relationship. For example if the value calculated of $r$ (ignoring the sign if it is negative) is equal to or larger than the critical value then there is a significant correlation at the 0.05 or $5 \%$.

The analysis results showed primarily that, the use of AR improves the followings; - Design presentation. - Client expectation. - Collaboration. • Project marketing. • Design modifications. • Design process. • Realistic image. • Decisionmaking. • Concept design. • Time, cost, and waste reduction. - Quantity of information sharing.

Table III shows the data from the Pearson Correlation analysis, including key descriptive statistical parameters: number of participants' responses, mean, standard deviation and significance. The variables in Table ?? were ranked according to their mean value, with the lowest mean results signifying the highest impact on the implementation of augmented reality in the project design life cycle. The correlation analysis presented in Table ?? assists in describing how strong is the relationship and the direction between the variables [36]. It is worth noting that the Pearson correlation analysis was performed to measure the strength of association between the 20 augmented reality factors and their implementation successes supposed by the participants. The analysis results in Table III show that from the 20 factors tested by Pearson Correlation only 14 factors have significant correlation $(\mathrm{p}<0.01)$, ( $\mathrm{r})$ value range between $(-1$ to +1$)$ probability level, between the variables. The 14 augmented reality factors were positive, indicating that those respondents assign relatively high importance to dealing with these factors and tend to implement them effectively.

\section{B. Analysis of qualitative survey}

This section shows the results of the qualitative feedback of survey using the convergent mixed method, based on the semistructured interviews data collection and analysis. A thematic approach was implemented to analyze the collected data from 18 interviewees.

Theme: Project Strategies and Augmented Reality: from the qualitative feedback, it was found that the application of different strategies is the most significant problem affecting project development, collaboration and decision-making. Moreover, the adoption of BIM is vital. However, several participants stated that there are several challenges and barriers in applying BIM, e.g. the use of different BIM software and the lack of cross compatibility of different software, unclear roles and responsibility of each discipline. Interestingly, it was suggested that the most significant barrier to BIM is the lack of demand from clients and perception of unviability of setup costs of BIM for medium and small size project. Additionally, other barriers include the lack of national standards, high cost of the software and its implementation, lack of skilled professionals, process problem within the organizations, legal issues, and license problems.

In summary, the key findings from the interviews are the following:

- Clear disconnection in the construction industry, due to the use of different strategies within the supply chain.

- BIM as collaboration strategies were not used directly through the construction stage.

- There are several issues related to the design stage, including the client involvement, the understanding of the client needs and requirements, and the interpretation of these requirements into a building design. The process is dynamic and has several tasks working in parallel, and therefore there will be several problems that can influence the project development and outcomes.

- Participants are interested in the implementation of augmented reality during design and construction phases.

- Augmented reality has the potential to change how the design and construction were processed, and the professionals and non-professionals can get involved, interact and experience the surrounding environment.

- Augmented reality enhances the reduction of errors during the design and the construction stages by better 
TABLE I

THE USE OF AUGMENTED REALITY WITHIN THE AGE CATEGORY OF THE PARTICIPANTS

\begin{tabular}{|lc|c|c|c|c|c|}
\hline \multicolumn{7}{c}{ Percentage within age range with the use of augmented reality } \\
\hline \hline Groups & $>20$ & $21-30$ & $31-40$ & $41-50$ & $<50$ & Total \\
\hline Used augmented reality & 13 & 32 & 28 & 23 & 14 & 110 \\
Did not use augmented reality & 10 & 13 & 11 & 12 & 7 & 53 \\
Total & 23 & 45 & 39 & 35 & 21 & 163 \\
\hline \hline
\end{tabular}

TABLE II

USE OF AUGMENTED REALITY WITHIN THE JOB ROLE CATEGORY OF THE PARTICIPANTS

\begin{tabular}{|c|c|c|c|c|c|c|c|}
\hline \multicolumn{8}{|c|}{ Percentage within job role range } \\
\hline & \multicolumn{3}{|c|}{ Design team } & \multicolumn{2}{|c|}{ Site team } & Others & \\
\hline & Architect & Service Eng. & Structure & Contractor & Sub-contractor & Client & Total \\
\hline Used augmented reality & 41 & 22 & 10 & 15 & 9 & 17 & 114 \\
\hline Did not use augmented reality & 14 & 7 & 9 & 5 & 5 & 9 & 49 \\
\hline Total & 55 & 29 & 19 & 20 & 14 & 26 & 163 \\
\hline
\end{tabular}

TABLE III

PEARSON'S CORRELATION RESULTS BETWEEN THE USE OF AUGMENTED REALITY AND THE VISUAL DESIGN PRESENTATION FACTORS

\begin{tabular}{|l|c|c|c|c|c|c|}
\hline \multicolumn{7}{|c|}{ Significant correlation: $\mathrm{p}<0.01$ (2-tailed) } \\
\hline \hline AR Factors & $N$ & Means & Std. Dev. & $R$ & Sig & Correlation \\
\hline Design presentation & 163 & 1.01 & 0.110 & $0.599^{* *}$ & 0.000 & Significant \\
\hline Increase the client collaboration & 163 & 1.02 & 0.156 & $0.615^{* *}$ & 0.001 & Significant \\
\hline Improve the project marketing & 163 & 1.02 & 0.137 & $0.456^{* *}$ & 0.001 & Significant \\
\hline Ease in detecting errors & 163 & 1.03 & 0.177 & $0.594^{* *}$ & 0.005 & Significant \\
\hline Improve the client expectation & 163 & 1.04 & 0.191 & $0.321^{* *}$ & 0.001 & Significant \\
\hline Better design modifications & 163 & 1.04 & 0.221 & $0.436^{* *}$ & 0.000 & Significant \\
\hline Enhance the design process & 163 & 1.05 & 0.274 & $0.590^{* *}$ & 0.005 & Significant \\
\hline Realistic image via service provided & 163 & 1.05 & 0.246 & $0.736^{* *}$ & 0.000 & Significant \\
\hline Enhance design decision-making & 163 & 1.05 & 0.218 & $0.621^{* *}$ & 0.001 & Significant \\
\hline Inter disciplinary collaboration & 163 & 1.06 & 0.244 & $0.445^{* *}$ & 0.002 & Significant \\
\hline Improve the team work & 163 & 1.06 & 0.255 & $0.463^{* *}$ & 0.001 & Significant \\
\hline Understanding the industry & 163 & 1.06 & 0.225 & 0.007 & 0.212 & Insignificant \\
\hline Improve concept design development & 163 & 1.06 & 0.255 & $0.521^{* *}$ & 0.000 & Significant \\
\hline Enhance information sharing & 163 & 1.07 & 0.328 & $0.644^{* *}$ & 0.001 & Significant \\
\hline Reduce time, cost, and waste & 163 & 1.11 & 0.414 & 0.125 & 0.118 & Insignificant \\
\hline Increase the quantity of information across team & 163 & 1.14 & 0.343 & $0.221^{* *}$ & 0.006 & Significant \\
\hline Maximise efficiency & 163 & 2.14 & 0.631 & 0.073 & 0.372 & Insignificant \\
\hline Improve the quality of the design & 163 & 2.30 & 0.881 & 0.021 & 0.794 & Insignificant \\
\hline Reduce risk & 163 & 2.59 & 0.505 & -0.125 & 0.116 & Insignificant \\
\hline Efficient tool & 163 & 2.86 & 0.345 & 0.049 & 0.539 & Insignificant \\
\hline \hline
\end{tabular}

reviews of the project outcome, and identifying problems and errors prior to the start of the work on site or even during the different construction stages.

- The visual augmented reality presentation and the virtual tour for the unskilled client, will lead to better marketing strategies.

As discussed above, the use of augmented reality will enhance the delivery of both design and construction stages, by enhancing the visualisation of the project design even before the start of the construction on site.

\section{Amalgamation of the results (triangulation)}

The validation took place after the interpretation of qualitative and qualitative data [38], [37], [35]; this involved the combination of both results to build the theoretical and practical foundation in order to develop the ARGILE Statistical findings show that; the participants' interests in the use of augmented reality throughout several stages of design-constriction processes. However, the participants' show less impact of few factors which are: $\bullet$ Maximise efficiency. Improve the quality of the design. • Reduce risk. • Efficient tool. • Understand the industry. - Reduce time, cost, and waste.

In addition, the interviews findings show that; there is a clear disconnect in the construction industry, the availability of several tools to present and share data, and the interest in the use of augmented reality to overcome the research problems and limitation within the visual understanding of the project design.

Further, the combination and the triangulation of the results showed the need to:

- Improve collaboration via developing project strategy (Figure 2)

- Improve decision-making

- Enhance over all collaboration

- Empower visual understanding via augmented reality. 
The points mentioned above will be used to design and develop the ARGILE conceptual framework by combining Agile and Augmented reality.

\section{ARGILE conceptual framework}

The proposed ARGILE framework is started from the project strategy. Another key issue has been used in developing the proposed ARGILE framework is communication and collaboration.

The proposed ARGILE framework (see Figure 2) needs a set of requirements, including the following:

- Cycle one "Plan": a supportive way to permit the professional and non- professional to be involved in the design-construction processes throughout the project life cycle. Additionally, a mechanism that prioritizes both the requirements for the project and the solution to those requirements, which can be accurately predicted in advance;

- Cycle two "Implementation": a collaboration method between professionals, of sharing the project requirements and the implementation of the requirements according to the information received from the first cycle plan.

- Cycle three "Collaborate": a mechanism that defines communication and collaboration, ensuring all data and information shared between the professional and nonprofessional can be managed and processed. Furthermore, it allows using augmented reality for visual testing of each task, and creating experience that is more effective.

- Cycle four "Deliver": delivering the tasks incrementally, by ordering them based on MoSCoW prioritization technique. This, therefore, could result in substantial savings in development costs.

Figure 2 shows details of the ARGILE conceptual framework and its cycles. The main advantage of ARGILE conceptual framework is the client involvement through the whole project life cycle; as in the end, it is the client satisfaction with the project outcome, which is important. When the client is involved and able to engage with the process and make changes to the design during the project development, and during the construction stages, this would lead to a more successful project outcome, and would increase the client satisfaction. As specified earlier, one of the main issues within the construction sector is the lack of collaboration, communication, and decision-making. Thus, one of the main features of the ARGILE framework is the work in cycles (scrum and sprint), which last from two week to four weeks (depending on the task undertaking). Within these cycles there are daily meetings aiming at setting out the tasks, reviewing the efficiency of completed tasks, and discussing the current tasks that need to be done in the coming day. Furthermore, at the end of each cycle, a meeting is held to evaluate the tasks done through this cycle, and then a new task is held either in order to plan the coming cycle, or meet to collaboratively evaluate and plan for both tasks.

In addition, the proposed ARGILE framework offers the product backlog strategy normally created at the start of the project and developed collaboratively between the client and the project team depending on the client's requirements and it would be considered the foundation of the project development. By using the product backlog, the team can know precisely the project aim, its requirements and the quantity of resources needed. Besides, by continuously updating the backlog of the project it would create accurate schedules. Furthermore, at the start of any project the ARGILE strategy focuses on a strong communication plan including scheduling and planning meetings, leading to a solid project foundation.

Another advantage in the ARGILE framework is the time management, however currently several construction projects are using time management as well, but with the ARGILE framework approach, the intention is to break up the tasks into small tasks and develop each of them incrementally by using a fixed-length of time a time box. The implementation of augmented reality within the proposed ARGILE framework as a visual testing tool increases client understanding of the tasks output enhances client involvement and collaboration with the project team. In summary, the proposed ARGILE framework is a proactive process and adapts changes to enhance valued project outcomes.

\section{CONCLUSIONS}

The present study was designed to highlight the problems related to the design and construction stages of any project, such as fluctuation in collaboration, decision-making, the lack of communication between professional and non-professional project stakeholders and problems related to the visualisation tools and testing. As shown in this study, the proposed ARGILE framework could be used by practitioners to deliver tasks on time and effectively. The iterative approach encourages detailing to merge over time. The current step needs to be completed in only enough detail to allow the project to move to the next stage, with any shortfall in detailed understanding being dealt with in subsequent iterations of development. Given the very strong likelihood that project requirements will change over time, and that such change is most likely to happen at the detail level, the effort traditionally spent on detailed up-front work is avoided in ARGILE. Solution build using the ARGILE approach addresses the current and imminent needs of the project rather than, the traditional approach of attacking all the perceived possibilities.

This study has further shown that, with ARGILE framework, every decision taken during the delivery of the project should be viewed in the light of the overriding project goal. Moreover, the ARGILE framework encourages increased understanding, and decision-making. The level of the quality to be delivered should be agreed on at the start, and thus the work should be aimed at achieving that level of quality. One of the key differentiations for ARGILE is the concept of establishing firm foundations for the project before committing to significant development. As ARGILE, advocates first understanding the scope of the project requirements, to be proposed solution but not in such details. Once the foundations 


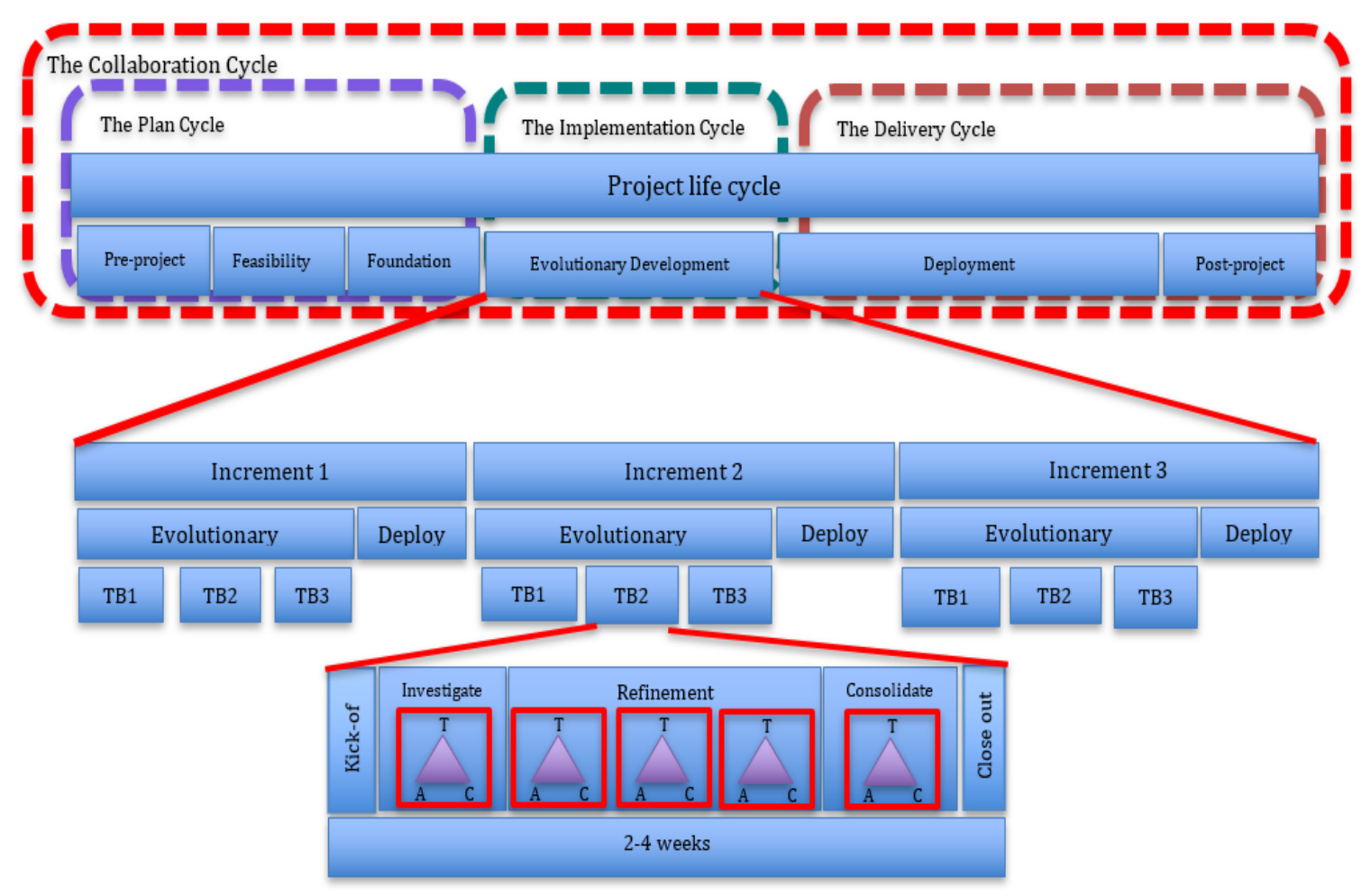

Fig. 2. Detailed representation of the proposed ARGILE conceptual framework and its cycles

for the development have been established ARGILE advocates incremental delivery.

The results of this study indicate that the proposed ARGILE framework uses a combination of iterative development, frequent test and comprehensive review to encourage timely feedback. Embracing change as part of this evolutionary process allows the team to converge on an accurate solution. Poor communication and collaboration is often cited as the biggest single cause of project failure, thus, ARGILE is specifically designed to improve communication and collaboration effectiveness for both team and individuals. The use of the ARGILE approach here helps in the development of new ways of thinking, additionally it helps in gaining an understanding of the essential principles of the ARGILE process at a shallower level in order to understand why they make sense and how ARGILE could add value to fit the situation and go beyond the traditional method. For any project planning required in advance, the question here is how far in the future should the project be planned out?

The planning approach is precisely connected to the uncertain level in any project, and thus, the planning tactic tries to decrease this level of uncertainty to an adequate level dependent on the complication of the project. In ARGILE, the main process is the time taken for planning. Traditionally, it could be believed that the accomplishment of any project is in how much detail the project was planned. While ARGILE, however, will not plan so far in the future, as it is impossible to guess what will happen. Alternatively, a shorter time into the future could be planned and gradually more detail could be added into it.

Moreover, the ARGILE approach has identified the need for taking a more evolving tactic to plan. Once the project is developed, the requirements and the planning will be further expanded. The idea behind this approach is that planning too far in the future obviously includes some conclusions and assumptions. Quite a lot of these assumptions are inappropriate, resulting in re-planning; also it could necessitate modification or reworking of any task based on inaccurate assumptions. Alternatively, postponing or delaying the planning decisions could yield better results as additional information will be presented at that point in time to make those decisions with fewer assumptions. One significant contribution of this study is in enhancing the understanding of agile and augmented reality approaches for identification, evaluation, integration and client involvement and expectation during project delivery. There is a need for the construction sector to develop further its appreciation of adaptive and predictive planning. This calls for a comprehensive research into the role of adaptive and predictive construction project planning.

\section{REFERENCES}

[1] Peterson, S., Braun, S., Salazar, J. and Balmaseda, M.S., 2017. Accelerating Pre-construction Project Delivery (No. 17-05044).

[2] Martin, H., Lewis, T., Peters, E. and Petersen, A., 2017. Construction project delivery cloud decision-support model. Proceedings of the Institution of Civil Engineers-Management, Procurement and Law, 170(1), pp.6-26. 
[3] Ross, A., Marsh, D. and Manewa, A. (2016). Is construction getting quicker? The 5th world construction symposium, 29-31 July.

[4] Shah, R.K., Dawood, N.N. and Castro, S., 2008. Automatic generation of progress profiles for earthwork operations using 4D visualisation model. International Journal of Information Technology in Construction. ISSN 14036835

[5] Merschbrock, C., 2012. Unorchestrated symphony: The case of inter organizational collaboration in digital construction design. Journal of Information Technology in Construction (ITcon), 17(22), pp.333-350. ISSN 1874-4753

[6] Dearlove, J. and Saleeb, N., 2016. Intelligent Decision-Making System Frameworks for a Digital Plan of Work: A Theoretical Investigation for the Construction Industry.

[7] Wu, C., Xu, B., Mao, C. and Li, X., 2017. Overview of BIM maturity measurement tools. Journal of Information Technology in Construction (ITcon), 22(3), pp.34-62. doi:10.1016/j.proeng.2017.01.214.

[8] Chen, K. and Li, H., 2015, December. AHP based weighting system for BIM implementation and assessment framework. In Industrial Engineering and Engineering Management International Conference (pp 1727-1731). doi:10.1109/ieem.2015.7385943.

[9] Sun, C., Jiang, S., Skibniewski, M.J., Man, Q. and Shen, L., 2017. A literature review of the factors limiting the application of BIM in the construction industry. Technological and Economic Development of Economy, 23(5), pp.764-779. doi:10.3846/20294913.2015.1087071.

[10] Kim, S.A., Choe, Y., Jang, M. and Seol, W., 2011. Design process visualization system intergrating BIM data and performance-oriented design information. In Proceedings of the 28th International Symposium on Automation and Robotics in Construction. doi:10.22260/isarc2011/0136.

[11] Borgmann, A., 2008. Reality and technology. Cambridge Journal of Economics, 34(1), pp.2735. Doi: 10.1093/cje/ben055

[12] Ambler, S.W., Agile ModelDriven Development (2002). The Object Primer, pp.101133. Doi:10.1017/cbo9780511584077.007.

[13] Lines, M. and Ambler, S.W., 2015. Introduction to Disciplined Agile Delivery: A Small Agile Team's Journey from Scrum to Continuous Delivery. CreateSpace Independent Publishing Platform.

[14] Highsmith, J.A., 2002. Agile software development ecosystems (Vol. 13). Addison-Wesley Professional. IBSN: 0-201-76043-6

[15] Hall, D. and Lehtinen, T., 2015, June. Agile cost shifting as a mechanism for systemic innovations. In EPOC 2015 Conference Proceedings (pp. 1-15).

[16] Salo, O., and Abrahamsson, P., 2008. Agile methods in European embedded software development organisations: a survey on the actual use and usefulness of Extreme Programming and Scrum. IET software, 2(1), pp.58-64. Doi: 10.1049/iet-sen:20070038

[17] Landry, J. and McDaniel, R., 2016. Agile Preparation Within a Traditional Project Management Course. Information Systems Education Journal, 14(6), p.27.

[18] Boehm, B. and Turner, R., 2003. Observation on balancing discipline and agility. Proceedings of the Agile developemte Conference. ADC. Doi: $10.1109 /$ adc.2003.1231450

[19] Wise, T.P. and Daniel, R., 2015. Agile Readiness: Four Spheres of Lean and Agile Transformation. Gower Publishing, Ltd. ISBN 978-1-47241743-5.

[20] Sohi, A.J., Hertogh, M., Bosch-Rekveldt, M. and Blom, R., 2016. Does lean and agile project management help coping with project complexity?. Procedia-Social and Behavioral Sciences, 226, pp.252-259. Doi:10.1016/j.sbspro.2016.06.186.

[21] Loforte Ribeiro, F. and Timteo Fernandes, M., 2010. Exploring agile methods in construction small and medium enterprises: a case study. Journal of Enterprise Information Management, 23(2), pp.161-180. Doi:10.1108/17410391011019750

[22] Sinclair, D. (2013). RIBA Plan of Work 2013. London: RIBA.

[23] Tripp, J.F., Riemenschneider, C. and Thatcher, J.B., 2016. Job satisfaction in agile development teams: Agile development as work redesign. Journal of the Association for Information Systems, 17(4), p.267. doi:10.17705/1jais.00426

[24] Stapleton, J. ed., 2003. DSDM: Business focused development. 2nd, ed. Pearson Education.

[25] Owen, R., Koskela, L.J., Henrich, G. and Codinhoto, R., 2006, July. Is agile project management applicable to construction?. In Proceedings of the 14th Annual Conference of the International Group for Lean Construction (pp. 51-66).

[26] Evbota, F., Knauss, E. and Sandberg, A., 2016, May. Scaling up the planning game: Collaboration challenges in large-scale agile product de- velopment. In International Conference on Agile Software Development (pp. 28-38). Springer, Cham. Doi:10.1007/978-3-319-33515-5-3.

[27] Inayat, I. and Salim, S.S., 2015. A framework to study requirementsdriven collaboration among agile teams: Findings from two case studies. Computers in Human Behavior, 51, pp.1367-1379. Doi:10.1016/j.chb.2014.10.040.

[28] Carmigniani, J., Furht, B., Anisetti, M., Ceravolo, P., Damiani, E. and Ivkovic, M., 2011. Augmented reality technologies, systems and applications. Multimedia tools and applications, 51(1), pp.341-377. Doi:10.1007/s11042-010-0660-6.

[29] Hussein, A., 2015. The use of triangulation in social sciences research: Can qualitative and quantitative methods be combined?. Journal of comparative social work, 4(1).

[30] Agarwal, S., 2016. Review on application of augmented reality in civil engineering. In International Conference on Inter disciplinary Research in Engineering and Technology.

[31] Behzadan, A. and Kamat, V.R., 2012, November. A framework for utilizing context-aware augmented reality visualization in engineering education. In the 12th International Conference on Construction Application of Virtual Reality (pp. 5-8)

[32] Chi, H.L., Kang, S.C. and Wang, X., 2013. Research trends and opportunities of augmented reality applications in architecture, engineering, and construction. Automation in construction, 33, pp.116-122. Doi:10.1016/j.autcon.2012.12.017

[33] Zhou, Y., Luo, H. and Yang, Y., 2017. Implementation of augmented reality for segment displacement inspection during tunneling construction. Automation in Construction, 82, pp.112-121. Doi:10.1016/j.autcon.2017.02.007.

[34] Bryman, A. and Bell, E., 2015. Business research methods. Oxford University Press, USA. ISBN 978-0-19-968945-3

[35] Creswell, J.W. ,2014. Research Design: Qualitative, Quantitative, and Mixed Methods Approaches. 4th ed. London: Sage publications.

[36] Pallant, J., 2005. SPSS Survival Guide-A step by step guide to data analysis using SPSS for windows (Ver. 12).

[37] Rubin, A. and Babbie, E.R., 2016. Empowerment series: Research methods for social work. Cengage Learning. ISBN 978-1-305-63382-

[38] Tashakkori, A. and Teddlie, C., 2010. Sage handbook of mixed methods in social and behavioral research. 2nd ed. Sage. Publications. ISBN 9781-4129-7266-6

[39] Dubois, E. and Nigay, L., 2000, April. Augmented reality: which augmentation for which reality?. In Proceedings of DARE 2000 on Designing augmented reality environments(pp. 165-166). ACM.

[40] Mourtzis, D., Vlachou, A. and Zogopoulos, V., 2017. Cloud-based augmented reality remote maintenance through shop-floor monitoring: a product-service system approach. Journal of Manufacturing Science and Engineering, 139(6), p.061011 